\title{
Manifestations of immune tolerance in the human female reproductive tract
}

\section{Gary F. Clark* and Danny J. Schust*}

Department of Obstetrics, Gynecology and Women's Health, Division of Reproductive Medicine and Fertility, University of Missouri, Columbia, MO, USA

\section{Edited by:}

Rachel R. Caspi, National Institutes of Health, USA

Reviewed by:

Joan Stein-Streilein, Schepens Eye

Research Institute, USA

Andreas Meinhardt,

Justus-Liebig-University, Germany

${ }^{*}$ Correspondence:

Gary F. Clark, Department of

Obstetrics, Gynecology and

Women's Health, Division of

Reproductive Medicine and Fertility,

University of Missouri, 1 Hospital

Drive HSC M658, Columbia,

MO 65211, USA.

e-mail: clarkg@health.missouri.edu

Danny J. Schust, Department of

Obstetrics, Gynecology and

Women's Health, Division of

Reproductive Medicine and Fertility,

University of Missouri, 500 North

Keene Street, Suite 203, Columbia,

MO 65203, USA.

e-mail: schustd@health.missouri.edu
Like other mucosal surfaces (e.g., the gastrointestinal tract, the respiratory tract), the human female reproductive tract acts as an initial barrier to foreign antigens. In this role, the epithelial surface and subepithelial immune cells must balance protection against pathogenic insults against harmful inflammatory reactions and acceptance of particular foreign antigens. Two common examples of these acceptable foreign antigens are the fetal allograft and human semen/sperm. Both are purposely deposited into the female genital tract and appropriate immunologic response to these non-self antigens is essential to the survival of the species. In light of the weight of this task, it is not surprising that multiple, redundant and overlapping mechanisms are involved. For instance, cells at the immunologic interface between self (female reproductive tract epithelium) and non-self (placental trophoblast cells or human sperm) express glycosylation patterns that mimic those on many metastatic cancer cells and successful pathogens. The cytokine/chemokine milieu at this interface is altered through endocrine and immunologic mechanisms to favor tolerance of non-self. The "foreign" cells themselves also play an integral role in their own immunologic acceptance, since sperm and placental trophoblast cells are unusual and unique in their antigen presenting molecule expression patterns. Here, we will discuss these and other mechanisms that allow the human female reproductive tract to perform this delicate and indispensible balancing act.

Keywords: cervix, semen, trophoblast, immune privilege, human, vagina

\section{INTRODUCTION}

There are specific locations in human tissues and organs where alloantigens and autoantigens are tolerated by the immune system. This tolerance can exist indefinitely or for defined periods of time like pregnancy. This uncoupling of the adaptive immune response confers a physiological state known as immune privilege (Streilein, 1995). Evidence suggesting the existence of immune privilege was first obtained by van Dooremal, who documented the extended survival of murine skin xenografts in the anterior chamber of the dog eye in 1873 (van Dooremaal, 1873). Other well-established immune privileged tissues and organs include the uteroplacental unit (Medawar, 1953; Beer and Billingham, 1971), brain (Muldoon et al., 2013), testes (Li et al., 2012), and the prostate (Neaves and Billingham, 1979; Leibovitz et al., 2004).

Peter Medawar initially recognized that the mammalian fetus is an allograft due to the contribution of its foreign paternal alloantigens (Medawar, 1953). Unrelated surrogate mothers readily accommodate a completely foreign fetus as well as their own offspring, confirming that maternal histocompatibility is unnecessary. These observations indicate that the female reproductive tract is immune privileged during pregnancy. However, a sexually active woman's immune components must respond robustly to pathogens at all times, yet remain selectively tolerant to maleassociated antigens present in human seminal plasma and sperm. The goal of this review is to consider the current evidence describing how immune privilege is manifested in the female reproductive tract during pregnancy and semen exposure, both of which should otherwise provoke potent immune responses.

\section{IMMUNE PRIVILEGE DURING PREGNANCY}

\section{THE HUMAN ZONA PELLUCIDA (ZP)}

The mammalian egg is surrounded by the zona pellucida (ZP), which acts as a specialized extracellular matrix for binding sperm. For fertilization to occur, sperm must first bind to this matrix, transit through this barrier and fuse with the egg cell to form a zygote (Clark, 2010). The zygote is an equal combination of both the maternal and foreign paternal genomes. It is unknown at which stage the human pre-embryo begins to express paternal major histocompatibility (MHC) molecules. However, in the mouse, MHC expression is readily detected at the eight cell stage (Ewoldsen et al., 1987). Cytotoxic T lymphocyte cells (CTL) sensitized to paternal MHC antigens are unable to kill mouse preembryos surrounded by an intact ZP, but pre-embryos denuded of this matrix are immediately destroyed (Ewoldsen et al., 1987).

The ZP has been suggested to simply act as a physical barrier against the rejection of the human pre-embryo (Ewoldsen et al., 1987). However, many types of immune cells transit through similar types of physical barriers during the rejection of a foreign organ transplant (Krensky et al., 1990). Human ZP glycoproteins express $\mathrm{N}$-glycans terminated with multivalent sialyl-Lewis ${ }^{\mathrm{x}}$ sequences (SLEX) that mediate sperm binding (Figure 1) (Pang et al., 2011). SLEX is also the universal ligand for the selectins, 


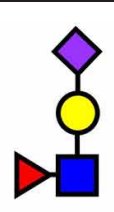

Sialyl-Lewis ${ }^{x}$

(SLEX)

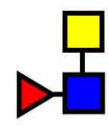

Fucosylated

LacdiNAc<smiles>OC1CCC12CC2</smiles>

DQ

Lewis $^{\mathrm{x}} \quad$ Lewis $^{\mathrm{y}}$

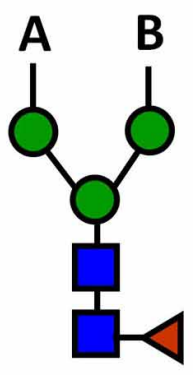

Biantennary

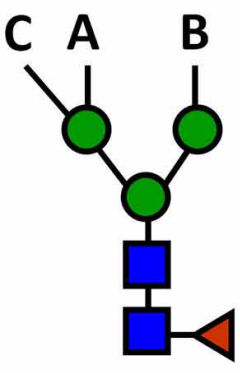

Triantennary

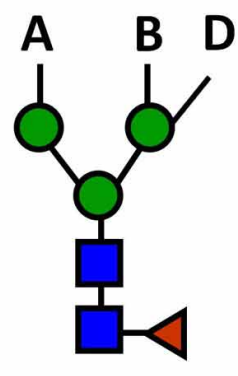

Triantennary

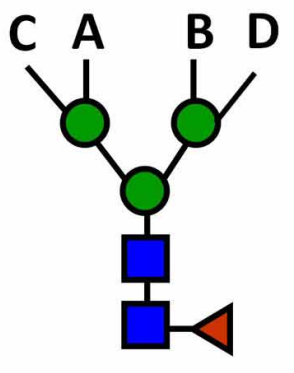

Tetraantennary

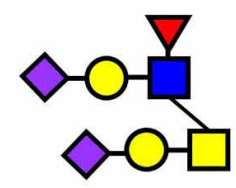

UM-1

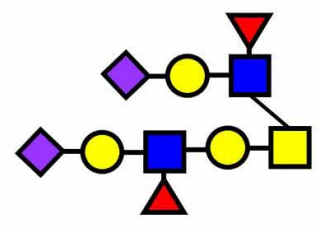

UM-2

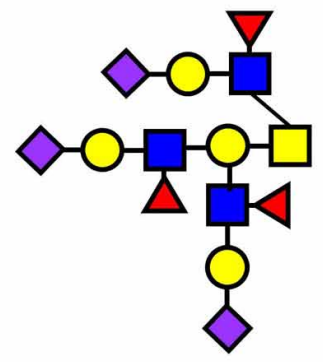

UM-3
FIGURE 1 | Carbohydrate sequences involved in immune privilege in the human reproductive system. N-glycans usually have two (biantennary), three (triantennary), or four (tetraantennary) antennae linked at up to four positions (designated A-D). On the human ZP, there are biantennary and triantennary $\mathrm{N}$-glycans terminated on every antenna with the SLEX sequences on every antenna (Pang et al., 2011). Tetraantennary $\mathrm{N}$-glycans bearing three SLEX antenna are also present. Human sperm and seminal plasma express bi-, tri-, and tetra-antennary $\mathrm{N}$-glycans terminated exclusively with Lewis ${ }^{x}$ or exclusively with Lewis $^{y}$ sequences on their antennae, though many carry a mixture of both of these sequences (Pang et al., 2007, 2009). Glycodelin-A bears the fucosylated lacdiNAc sequence on $60 \%$ of its total N-glycans (Dell et al., 1995). Uromodulin expresses one (UM-1), two (UM-2), or three SLEX sequences on a single O-glycan (Easton et al., 2000). These types of presentations have not been found in other normal cells or tissues outside of the human reproductive system. cell adhesion molecules that mediate both the binding of immune cells to inflamed vascular endothelium and lymphocyte homing (Foxall et al., 1992; Fukuda et al., 1999). SLEX is also a ligand for siglec-9, an immunoglobulin-like lectin that carries an immunoreceptor tyrosine-based inhibitory motif (ITIM) that generates an inhibitory signal in several immune cell populations (Angata and Varki, 2000; Avril et al., 2004). The possibility has been raised that the carbohydrate sequences expressed on the ZP act as functional groups to protect the early pre-embryo before blastocyst hatching (Clark et al., 1996, 1997). In short, the human egg itself could be an immune privileged cell type both before and after fertilization.

\section{GLYCODELIN-A (Gda) AND CA125}

When the histoincompatible human pre-embryo hatches out of the blastocyst, it faces the daunting task of invading the maternal endometrial lining where four major immune cell populations are present: uterine $\mathrm{NK}$ cells ( $\mathrm{uNK}$ ), macrophages, $\mathrm{T}$ cells, and 
dendritic cells (DC) (King et al., 1998; Tirado-Gonzalez et al., 2012). During the early stages of implantation, trophoblast cells secrete the chemokine MIP- $1 \alpha$ that induces uNK cells and monocytes to migrate to the implantation site, resulting in the formation of a dense infiltrate of these cells in the decidua basalis (Drake et al., 2001). It is apparent that the implanting human embryo is challenged at an early stage by these immune cells. One major question becomes apparent: how does the encircled human embryo resist challenge by these immune cells at this early stage?

Glycodelin-A (GdA) (PP14) is a luteal phase endometrial glycoprotein that is secreted beginning 2 days after ovulation (Dalton et al., 1995). This $27 \mathrm{kDa}$ glycoprotein manifests many different immune deviating effects when present at physiological concentrations in vitro (Table 1). If implantation succeeds, the synthesis of GdA is massively induced, becoming $4-16 \%$ of the total protein content expressed in early stage decidua (7-11 weeks of pregnancy) (Julkunen et al., 1985). GdA is also taken up by the placenta and concentrated in this organ. This glycoprotein is also present in physiologically relevant concentrations in amniotic fluid, reaching levels averaging $46 \mu \mathrm{g} / \mathrm{ml}$ between 12 and 20 weeks (Julkunen et al., 1985). However, the level of GdA decreases dramatically after 20 weeks, becoming a minor component of decidual proteins and the amniotic fluid at term.

Glycodelin has also been isolated from seminal plasma and has been designated GdS. Its protein backbone is identical to GdA, but GdS does not cause the diverse immunomodulatory effects associated with GdA. Instead, in vitro studies indicate that it blocks the capacitation of human sperm (Chiu et al., 2005). Biophysical analyses of GdA and GdS confirm major differences in their N-glycosylation patterns. GdA expresses very unusual fucosylated lacdiNAc and $\mathrm{Sd}^{\mathrm{a}}$ sequences on the antennae of its $\mathrm{N}$-glycans; these are completely lacking in GdS (Morris et al.,

Table 1 | Immunomodulatory activities of Glycodelin-A.

\begin{tabular}{ll}
\hline Effect & References \\
\hline $\begin{array}{l}\text { Inhibits T cell proliferation by PHA and } \\
\text { other activators }\end{array}$ & Pockley et al., 1988 \\
Decreases production of IL-2 following & Pockley and Bolton, 1989 \\
T cell activation & \\
Induces apoptosis of activated T cells & Mukhopadhyay et al., 2001 \\
$\begin{array}{l}\text { Binds CD45 on T cells via a potential } \\
\text { lectin-like activity }\end{array}$ & Ish-Shalom et al., 2006 \\
$\begin{array}{l}\text { Inhibits lysis of K562 target cells by large } \\
\text { granular lymphocytes }\end{array}$ & Okamoto et al., 1991 \\
$\begin{array}{l}\text { Diminishes IgM secretion and MHC class II } \\
\text { expression in B cells }\end{array}$ & Yaniv et al., 2003 \\
$\begin{array}{l}\text { Blocks chemoattractant induced migration } \\
\text { of monocytes }\end{array}$ & Mukhopadhyay et al., 2001 \\
$\begin{array}{l}\text { Inhibitor of E-selectin-mediated cell } \\
\text { adhesion }\end{array}$ & Jeschke et al., 2003 \\
$\begin{array}{l}\text { Stimulates IL-6 secretion by monocytes/ } \\
\text { macrophages via interaction with L-selectin } \\
\text { and the extracellular signal regulated kinase } \\
\text { pathway }\end{array}$ & Lee et al., 2012
\end{tabular}

1996; Lee et al., 2009). The fucosylated lacdiNAc sequence is a carbohydrate ligand for both selectins and DC-SIGN, two immune lectins that have been implicated in leukocyte/lymphocyte binding and the modulation of the adaptive immune response, respectively (Grinnell et al., 1994; van Liempt et al., 2006). The carbohydrate sequences linked to GdA have been implicated as functional groups that enable this glycoprotein to mediate its immunomodulatory effects (Clark et al., 1996, 1997).

CA125 (MUC 16) is the largest mucinous glycoprotein in the human genome, coding for $\sim 24,000$ amino acids (Yin et al., 2002). It is best known for its role as a specific marker for epithelial ovarian cancer (Bast et al., 1981, 1983). CA125 isolated from the human ovarian cancer cell line, OVCAR-3, is heavily $\mathrm{N}$ - and $\mathrm{O}$-glycosylated, and its constituent glycans have been sequenced (Kui Wong et al., 2003). CA125 is secreted by endometrial epithelial cells during the same temporal window of the menstrual cycle as GdA (Kui Wong et al., 2003). Like GdA, this mucinous glycoprotein also becomes a major secreted product during the first trimester of human pregnancy. CA125 derived from OVCAR-3 cells suppresses cytotoxicity mediated by NK and lymphokine activated killer cells (LAK) in vitro when present at the physiological concentrations seen in the endometrium and decidua during the first trimester of pregnancy (Patankar et al., 2005). CA125 manifests this specific effect by blocking NK cell synapse formation, which results in the direct inhibition of NK cell mediated cytotoxicity (Gubbels et al., 2010).

In summary, GdA and CA125 likely participate in suppressing the maternal immune responses before implantation and continue to do so until mid-trimester. Defective expression of these glycoproteins during this stage of pregnancy would likely result in implantation failure or early pregnancy loss. However, whether defective expression of these modulators sets the stage for other pathological processes that are manifested after midtrimester is currently unknown.

\section{DIFFERENTIAL EXPRESSION OF HUMAN MAJOR HISTOCOMPATIBILITY (MHC) ANTIGENS}

The human leukocyte antigen (HLA) region of human chromosome 6 encodes many immune system genes, including the MHC complex class I and II molecules, which can be found on the surface of almost all nucleated cell types. HLA expression is tightly regulated at the feto-maternal interface, perhaps because direct engagement of foreign paternal or maternal antigens could trigger fetal rejection. When the human embryo first makes contact with the maternal endometrial epithelium, placental trophoblast cells at the adhesion site fuse and form a syncytium of multinucleated cells called syncytiotrophoblast (SynT) cells. Unlike normal cells and tissues, SynT and the underlying villous cytotrophoblasts (CytoT) do not express HLA class I and class II molecules (Hutter et al., 1996). This unusual characteristic ensures that paternal HLA antigens that could trigger histocompatibility based immune rejection are not expressed on these invasive trophoblast populations.

This lack of HLA expression, however, is somewhat problematic from an immunological perspective. About $70 \%$ of the immune cells at the implantation site during the early stages of pregnancy are uNK cells (King et al., 1996). Though not as potent 
in this activity as peripheral NK cells, uNK cells lyse HLA negative cells based on the "missing self" hypothesis (King et al., 1989; Karre, 1991). Currently, there is no explanation for how SynT resist these NK cell-mediated responses, since they are somewhat sensitive to lymphokine activated killing (King and Loke, 1990). However, there are large amounts of GdA and CA125 in the uterus during implantation that could substantially affect uNK cell mediated cytotoxicity.

Further complexity in this system is added by the expression of uncommon HLA class I molecules on specific, highly-invasive trophoblast cell subpopulations. The placental villi are a complex series of branching structures that contain a core of fetal vessels surrounded by stroma (Figure 2). Separating the stroma and fetal vessels from the maternal blood present in the spaces between villous structures are an inner, non-continuous layer of villous cytotrophoblast cells (CytoT) and an outer, continuous layer of fused, multinuclear SynT cells (Georgiades et al., 2002). Some placental villae float freely in the intervillous space, while others traverse the space to attach or anchor themselves to the maternal decidualized endometrium (decidua). The third trophoblast cell type, extravillous cytotrophoblast (EVTB) cells arise at the tips of anchoring villae and invade deeply into the maternal decidua (Benirschke, 1994). Invasion in humans typically extends into the inner third of the uterine muscle (myometrium). EVTB also invade the maternal uterine vessels, called spiral arteries due to their anatomic appearance. EVTB plug maternal spiral arteries until approximately 10 weeks of pregnancy (Burton and Jauniaux, 2004) and remodel the vessel walls to convert them from highly vasoactive structures into relatively unresponsive conduits for blood flow from mother to baby. After 10 weeks of gestation, EVTB vascular plugs disappear to allow unobstructed flow through these conduits (Meekins et al., 1997).

EVTB are unlike all other human cells in their MHC class I expression. HLA-G and HLA-E are MHC class Ib molecules with restricted polymorphism that can be detected on the surface of EVTB (Juch et al., 2012). uNK cells bear inhibitory killer immunoglobulin-like receptors (KIR) that specifically recognize these molecules. HLA-E binds to CD94/NKG2A (King et al., 2000), whereas HLA-G binds to KIR2DL4 (Rajagopalan and Long, 1999). EVTB also express HLA-C, which is a polymorphic MHC class I molecule like HLA-A and HLA-B and couldbut does not appear to-strongly stimulate harmful antipaternal adaptive immune responses (Chazara et al., 2011). HLA-C molecules also specifically bind to NK cell KIRs.

\section{OTHER IMMUNOLOGICAL ACTIVITIES OF HLA-G}

Currently, seven different isoforms of HLA-G, designated G1-G7, have been identified. HLA-G1, -G2, -G3 and -G4 are membraneassociated forms whereas HLA-G5, -G6 and -G7 (Figure 3) are soluble forms (Favier et al., 2007b). Both soluble and membrane associated forms of HLA-G can induce many immunomodulatory effects in vitro (Hunt, 2006; Favier et al., 2007b). These include: (1) inhibition of NK cell-mediated responses by either soluble or cell surface associated forms; (2) abrogation of the lytic activity mediated by CTLs via either soluble or membrane bound isoforms; (3) suppression of the IFN- $\gamma$ mediated upregulation of CD8 $\alpha$ mRNA by recombinant soluble forms of HLA-G1 and HLA-G2; (4) inhibition of the alloproliferative responses of $\mathrm{CD}^{+} \mathrm{T}$ cells as a membrane-bound molecule expressed by third party inert cells or by cells presenting a stimulating antigen;

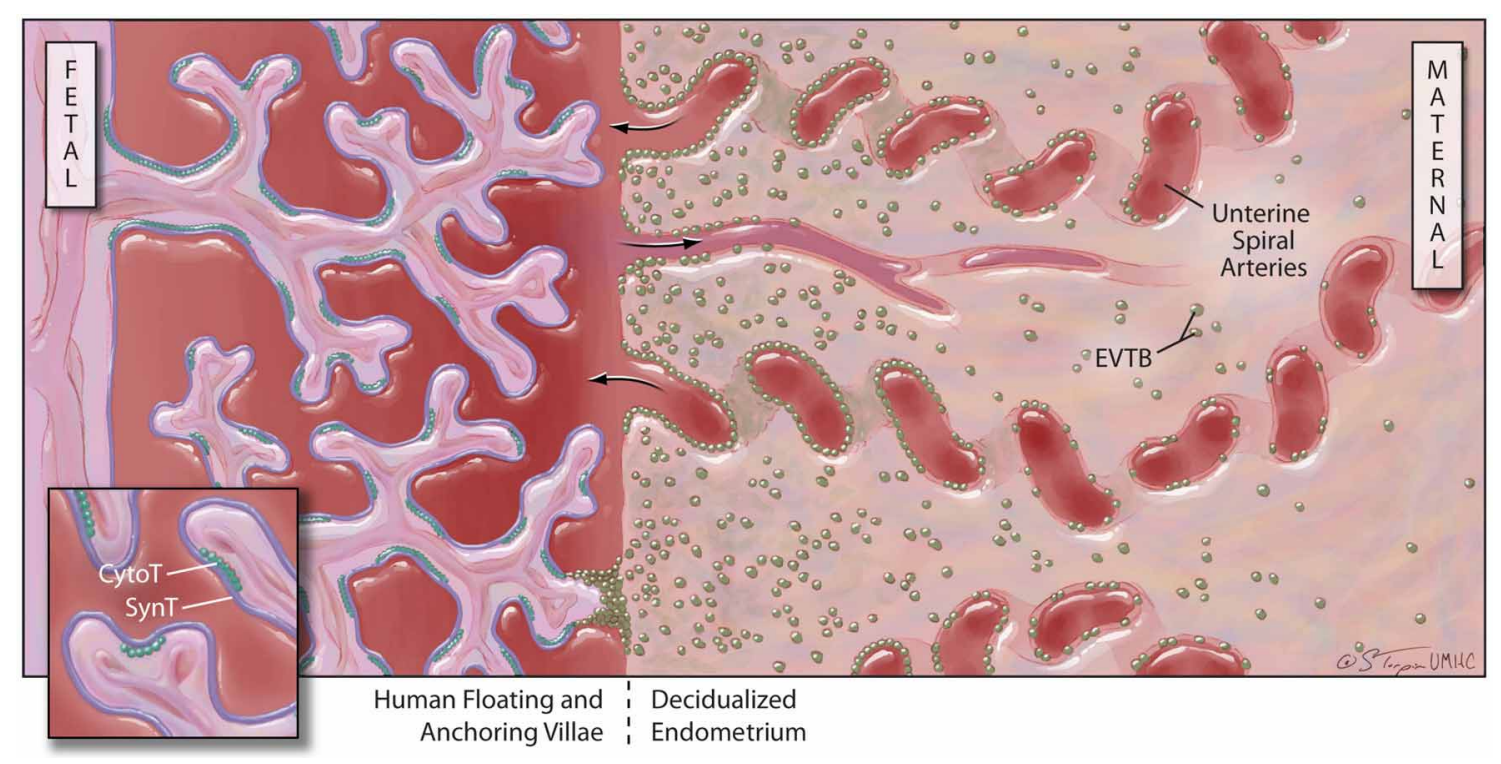

FIGURE 2 | Human placental structure (after 12 weeks of gestation): the human placenta has a fetal and a maternal side. The fetal side consists of a mass of tree-like villous structures that are bathed in maternal blood. Unlike floating villae, anchoring villae traverse the blood-filled intervillous space and attach to the maternal decidualized endometrium. The maternal decidua is populated by stromal and immune cells and is crossed by spiral arteries that dump blood into the intervillous space. Floating and anchoring placental villae are coated by an inner layer of individual, fetally-derived cytotrophoblast (Cyto-T) cells and an outer layer of fused syncytiotrophoblast (Syn-T) cells. A third population of fetally-derived trophoblast cells arises from Cyto-T at the tips of anchoring villae. These extravilous cytotrophoblast (EVTB) cells invade deeply into the maternal tissues and remodel maternal spiral arteries. 


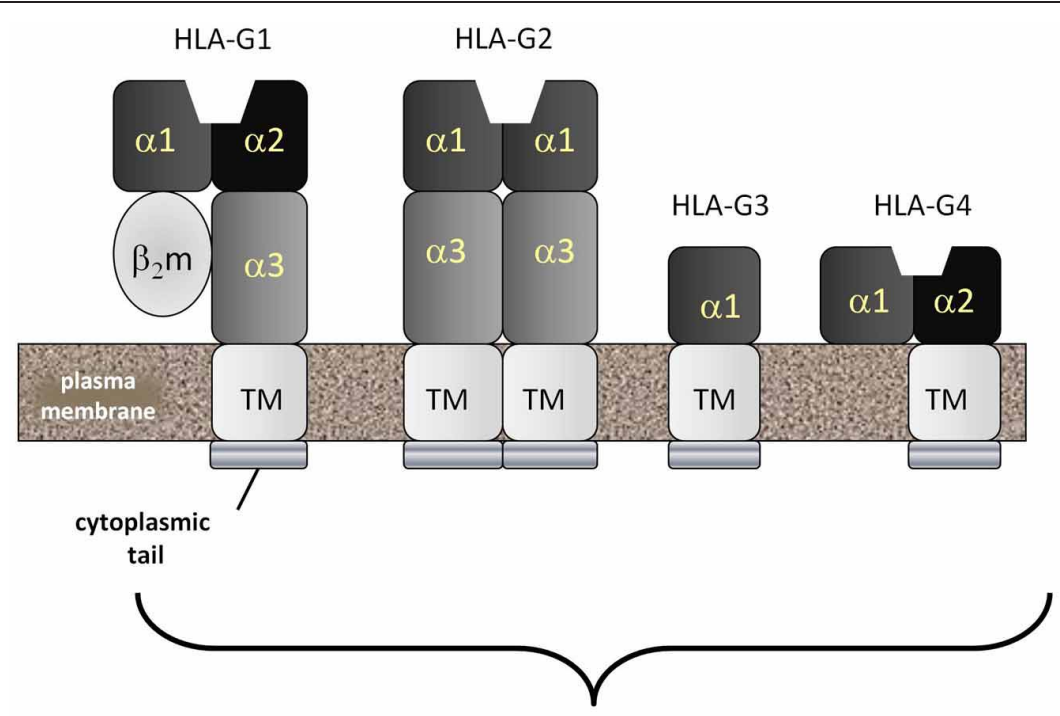

Membrane-bound
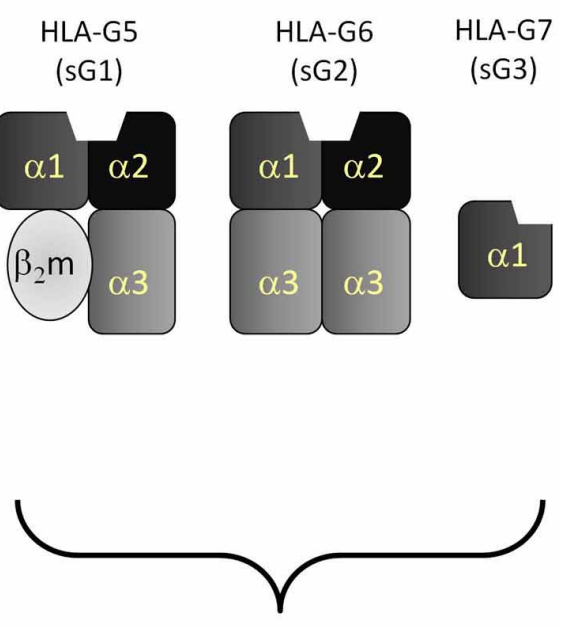

Soluble

FIGURE 3 | HLA-G: the most common form of the non-classical MHC class Ib molecule, HLA-G, mimics HLA-A and -B in structure and is called HLA-G1. HLA-A, $-B$ and $-G 1$ are all homodimers of an $\mathrm{MHC}$ class I heavy chain comprised of five domains and a stabilizing second molecule, beta- 2 microglobulin $\left(\beta_{2} \mathrm{~m}\right)$. The $\mathrm{MHC}$ class I heavy chain consists of an $\alpha 1$ and $\alpha 2$ domain (forming the antigenic peptide-binding groove), an $\alpha 3$ domain, a transmembrane domain and a cytopalasmic tail. Unlike classical MHC class I molecules, the cytoplasmic tail of HLA-G is very short, containing only six amino acids. Also unlike classical MHC class la molecules, HLA-G can be detected as several spliced variants. The most common of these are the membrane-bound HLA-G1, -G2, -G3 and -G4 and the soluble HLA-G5, -G6 and -G7. Soluble forms have lost their transmembrane segments and cytoplasmic tails during splicing.
(5) induction of the differentiation of Tregs by stimulating antigen-producing cells; and (6) disruption of DC maturation. These effects are mediated through direct binding to inhibitory receptors designated immunoglobulin-like transcript-2 and -4 (ILT2, ILT4) and the KIR, KIR2DL4 (Favier et al., 2007a). ILT2 is expressed by both myeloid and lymphoid cells. ILT4 is exclusively expressed by myeloid cells and KIR2DL4 is expressed by NK and some $\mathrm{T}$ cells bearing CD81.

The effects of HLA-G in vitro are quite varied and affect many different types of potential immune responses in the pregnant uterus. However, the exact protein levels of the soluble and cell surface-associated isoforms of HLA-G in the fetoplacental unit and in the maternal decidua and periphery have yet to be determined. There also remain questions about HLA-G expression in different physiological states, including the proposal that the soluble forms of HLA-G (HLA-G5, -G6, and -G7) are not present in the pregnant uterus at all (Blaschitz et al., 2005; Sargent, 2005). In fact, the functions of HLA-G during the early human implantation have been difficult to definitively establish. Specifically, decidual NK (dNK) cells do not reproducibly express KIR2DL4 and the interaction between this KIR and HLA-G has not been consistently demonstrated (Apps et al., 2008). In addition, Moffet et al. have recently shown that HLA-G has no effect on freshly isolated human dNK cells in several functional tests that are known to greatly affect peripheral blood NK cells (Apps et al., 2011).

\section{REGULATORY T CELLS (TREGS)}

Tregs are essential for the development of immune privilege in the uterus during early but not late mouse pregnancy (Aluvihare et al., 2004; Shima et al., 2010). In humans, these cells have a specific phenotype $\left(\mathrm{CD} 4^{+} \mathrm{CD} 25^{+} \mathrm{FoxP}^{+}\right)$and accumulate in the endometrium during the follicular phase of the menstrual cycle (Arruvito et al., 2007). These numbers are maintained if implantation proceeds, but otherwise decrease dramatically in the luteal phase. A decrease in the number of decidual Tregs during early pregnancy in women is correlated with spontaneous abortions (Sasaki et al., 2004). Tregs decrease the cytolytic activity of NK cells (Ghiringhelli et al., 2006), impede the development of DCs (Bluestone and Tang, 2005) and negatively impact the proliferation of and cytokine release by $\mathrm{CD}^{+} \mathrm{T}$ cells (Earle et al., 2005).

\section{GALECTINS}

Galectins are a family of small lectin molecules that generally have a universal affinity for $\mathrm{N}$-acetyllactosamine (galactose in $\beta 1-4$ linkage to N-acetylglucosamine; Gal $\beta 1-4 \mathrm{GlcNAc}$ ) but which can, in some cases, bind to other carbohydrate sequences (Barondes et al., 1994). For example, several galectins, including galectin-3, also bind to the Thomsen-Friedenreich (T-F) antigen ( $\mathrm{Gal} \beta 1$ 3GalNAc) (Bian et al., 2011). In 1983, placental protein 13 was the first galectin isolated from the female reproductive tract (Bohn et al., 1983). Galectin-1 is another major galectin that is found in villous CytoT. This galectin has been reported to induce $\mathrm{T}$ cell apoptosis (Perillo et al., 1995), although there is some debate about whether this effect was due to non-physiological incubation conditions (Stowell et al., 2007). Nonetheless, interest in the expression of human placental galectins increased substantially when galectin-1 deficient mice in a stress-induced model 
of pregnancy failure were reported to display higher rates of fetal loss than control mice (Blois et al., 2007). These investigators also demonstrated that this effect could be completely reversed by the administration of recombinant galectin-1. Galectin-1 has been proposed to mediate its effects via a variety of different mechanisms including: (1) differentially regulating the survival of Th cell subsets (Toscano et al., 2007; Motran et al., 2008); (2) controlling $\mathrm{T}$ cell trafficking ( $\mathrm{He}$ and Baum, 2006; Norling et al., 2008); and (3) promoting the differentiation of tolerogenic DCs (Ilarregui et al., 2009; Kuo et al., 2011). In one recent study, compelling evidence was provided that suggests the overall serum level of galectin-1 is decreased dramatically (eight-fold) in spontaneous abortion patients when compared to normal pregnant controls (Tirado-Gonzalez et al., 2013).

\section{INDOLEAMINE 2,3-DIOXYGENASE (IDO)}

Indoleamine 2,3-dioxygenase (IDO) is an enzyme that can be induced in specific macrophages following their stimulation with IFN- $\gamma$ and other mediators (Munn and Armstrong, 1993). Activation of this enzyme inhibits $\mathrm{T}$ cell-mediated responses by catabolizing the tryptophan that is essential for normal $\mathrm{T}$ cell proliferation. IDO is also synthesized by human Syn-T isolated from fresh placenta (Kamimura et al., 1991). Based on these effects, this enzyme was proposed to be a major mediator of immune tolerance during pregnancy. To test this hypothesis, Munn et al. exposed pregnant mice carrying either syngeneic or allogeneic fetuses to 1-methyl-tryptophan, a pharmacologic agent that inhibits IDO activity (Munn et al., 1998). Pregnant mice treated with this agent accommodated syngeneic but not allogeneic pups, suggesting IDO mediated tolerance. However, matings of male and female IDO-deficient mice generate litters of normal size, suggesting that the expression of IDO is not absolutely obligatory for mouse reproduction (Baban et al., 2004). Nonetheless, IDO likely plays a complementary role to other pregnancy-specific factors that insure the suppression of responses against the semiallogeneic fetus.

\section{UROMODULIN}

Tamm-Horsfall glycoprotein (THP) is the major protein/glycoprotein component in human urine (Tamm and Horsfall, 1950). Uromodulin is a differentially glycosylated form of THP that is present in the urine of pregnant human females, but not human males or non-pregnant females (Easton et al., 2000). It is 13 times more potent in the inhibition of antigeninduced $\mathrm{T}$ cell proliferation in vitro than THP derived from non-pregnant females and males (Hession et al., 1987). Rigorous analysis of uromodulin-derived oligosaccharides revealed the presence of unusual core 2 type O-glycans terminated with up to three SLEX terminals (Easton et al., 2000). By comparison, THP from non-pregnant females and males expresses very simple mono- and di-sialylated derivatives of Core 1 O-glycans, indicating a dramatic remodeling of THP glycosylation. Analysis of THP O-glycans isolated from females 2 months postpartum revealed a near total loss of SLEX modifications and a reversion back to forms that characterize the non-pregnant state. This observation suggests that uromodulin expression relies on human pregnancy hormones (e.g., estrogens, progesterone) or other related factors.
How uromodulin contributes to the maintenance of immune privilege during pregnancy remains an enigma.

\section{IMMUNE PRIVILEGE FOR SEMEN AND SPERM IN THE FEMALE REPRODUCTIVE TRACT}

The immune system in the human female reproductive tract is also challenged by both the cellular and soluble components of human semen. The vagina and the cervix represent a relatively hostile environment for human sperm (Drobnis and Overstreet, 1992). Soon after sexual intercourse, maternal neutrophils, monocytes, and lymphocytes are released from the cervical epithelium during a cellular response known as the leukocyte reaction (Pandya and Cohen, 1985; Thompson et al., 1992). Human sperm do not express paternal MHC class I or II molecules on their surface and should not trigger histocompatibility-based responses (Hutter and Dohr, 1998). However, immature germ cells, epithelial cells, and leukocytes are present in semen, although they usually comprise less than $15 \%$ of the total cellular fraction (Fedder, 1996). Unlike sperm, these cells express paternal MHC molecules that could stimulate an $\mathrm{MHC}$-restricted response at the surface of the cervico-vaginal epithelium (Zinkernagel and Doherty, 1974).

Sperm arise from testicular germ cells after the commencement of puberty and long after the period of thymic education (Fijak and Meinhardt, 2006). Proteins that are unique to human sperm are therefore foreign to the immune system and could be classified as either autoantigens or neoantigens. Evidence favoring this categorization includes the known induction of autoimmune orchitis following the autologous injection of testicular homogenates at sites distal to the testes (Tung et al., 1981). However, allografts and xenografts resist rejection following transplantation into the testis itself (Head and Billingham, 1985). This immune privileged state was initially thought to be due to the presence of a blood-testis barrier that protected germ cells from immune effector cells and antibodies (Setchell, 1967; Dym, 1973). Arguing against this paradigm is the fact that germ cell neoantigens on spermatogonia and early spermatocytes can be found in the basal compartments of the testis, which lack the blood-testis barrier (Yule et al., 1988; Saari et al., 1996). Further, neoantigens can also be detected in seminal plasma, which contains components that are produced by several glands in the male urogenital tract (Gupta et al., 1988).

Many of the known sperm and seminal plasma neoantigens are produced in response to androgen stimulation. While these antigens should provoke a potent immune response in the female reproductive system, the incidence of women with antisperm antibodies is only $2-3 \%$. When antibodies are produced, however, subfertility or infertility often follows (Rumke and Hellinga, 1959; Lombardo et al., 2001). Allergic reactions to the fluid components of seminal plasma are also rare (Sublett and Bernstein, 2011). These results suggest that powerful immune-deviating effects are in play within the female genital tract.

Based on the excellent outcomes of IVF and artificial insemination procedures, which separate germ cells from seminal plasma, it is apparent that seminal plasma components are not required for successful fertilization. On the other hand, exposure to seminal plasma may be crucial to reductions in certain disease 
states in humans. Preeclampsia is a common but incompletely understood complication of pregnancy with pleomorphic pathological effects (Pennington et al., 2012). Interestingly, women who have had prolonged exposure to semen via unprotected oral or vaginal sex exhibit a considerably lower risk of developing preeclampsia than women who have had a much more limited duration of semen exposure (Basso et al., 2001; Kho et al., 2009). These results lead to the conclusion that seminal plasma suppresses specific immune responses in the female reproductive tract and, in several instances, tolerizes the female to paternal immune challenges. The net effect would be to protect the female from other immune-related disease states of pregnancy. Several factors in seminal plasma have been proposed to be responsible for this immune deviation.

\section{PROSTAGLANDINS}

Human seminal plasma contains very high concentrations of prostaglandins when compared to other bodily secretions. These bioactive compounds were initially independently identified in this fluid by von Euler and Goldblatt in 1935 (Goldblatt, 1935; von Euler, 1935, 1936). Prostaglandin $\mathrm{E}_{1}, \mathrm{E}_{2}, \mathrm{E}_{3}, \mathrm{~F}_{1 \alpha}$, and $\mathrm{F}_{2 \alpha}$ have been detected in human seminal plasma (Samuelsson, 1963). It is now apparent that $\mathrm{PGE}_{2}, 19$-hydroxyprostaglandin $\mathrm{E}_{1}$ and 19-hydroxyprostaglandin $\mathrm{E}_{2}$ are the three major prostaglandins in human seminal plasma, each being present in millimolar concentrations (Taylor and Kelly, 1974; Kelly et al., 1976; Templeton et al., 1978). Since these lipid mediators often manifest their effects in the $\mu \mathrm{M}$ to $\mathrm{nM}$ concentration range, virtually all pathways that are affected by these lipids are operating under saturating conditions in human semen.

$\mathrm{PGE}_{2}$ is a potent modulator of immune function. The effects of $\mathrm{PGE}_{2}$ have been the subject of intense investigation for over 20 years because of its association with cancer and other pathological states. This prostaglandin can simultaneously manifest both proinflammatory and immunosuppressive effects. These effects are summarized with references in Table 2.

The overall effects of $\mathrm{PGE}_{2}$ include: (1) inhibition of responses mediated by phagocytic cells (neutrophils, macrophages); (2) suppression of NK, CTL, and T helper type 1 responses; (3) activation of DCs but limitation of their ability to attract naïve, memory, and effector T cells; and (4) stimulation of the production of regulatory $\mathrm{T}$ cells and myeloid-derived suppressor cells. In summary, the effects of $\mathrm{PGE}_{2}$ are consistent with a role in the inhibition of antigen-driven Th1 responses and in the promotion of Th2 responses. This overall response is essentially that which would be necessary to suppress responses directed against neoantigens while simultaneously maintaining the effectiveness of select beneficial immune responses.

\section{CYTOKINE EXPRESSION}

Human seminal plasma contains substantial amounts of a potent immunoregulatory cytokine known as transforming growth factor- $\beta$ (TGF- $\beta$ ) (Nocera and Chu, 1993), although only $\sim 7 \%$ of TGF- $\beta$ in seminal plasma is in the active form (Nocera and Chu, 1995). Latent TGF- $\beta$ can be activated by acidic conditions (transient acidification to $\mathrm{pH}$ 3.2) (Wakefield et al., 1987). Still, even though the healthy vaginal environment is acidic at baseline, it is unlikely that a significant amount of TGF- $\beta$ is activated here after deposition in the vagina because the buffering capacity of the relatively large volume of basic human seminal plasma causes the $\mathrm{pH}$ of the vaginal environment to increase from 4.3 to 7.2 within $8 \mathrm{~s}$ after ejaculation (Fox et al., 1973).

The levels of other cytokines in human seminal plasma have also been studied (Maegawa et al., 2002). The levels of IL-1 $\alpha$, IL-2, IL-4, IL-6, IL-8, TNF- $\alpha$, interferon- $\gamma$, granulocyte colonystimulating factor $[\mathrm{G}-\mathrm{CSF}]$ and macrophage CFS [M-CSF] have been analyzed. The pro-inflammatory cytokines (IL- $1 \alpha$, TNF- $\alpha$ ), chemokine (IL-8) and G-CSF are present, but at low levels. The remainder are undetectable. In short, the levels of inflammatory cytokines in the lower female genital tract are very low under normal physiological conditions.

Very elegant, but difficult to perform investigations have been conducted to assess the effects of seminal plasma on cytokine expression in the human cervix. Twelve hours after unprotected vaginal intercourse with ejaculation, the mRNA levels for colony stimulating factor 2, IL-6. IL- 8 and IL- $1 \alpha$ in human cervical biopsies are enhanced when compared to controls (abstention or condom-protected controls) (Sharkey et al., 2012b). Seminal fluid not only induces the expression of pro-inflammatory cytokines and chemokines in the cervix, but also causes a major influx of macrophages, DCs, and memory T cells (Sharkey et al., 2012b). Still, TGF- $\beta$ has been the component of seminal plasma most directly implicated in this response (Sharkey et al., 2012a).

\section{UNUSUAL GLYCOSYLATION OF HUMAN SPERM AND SEMINAL PLASMA GLYCOPROTEINS}

The role of glycosylation in inducing immune privilege, particularly in the reproductive tract, has been understudied. Historically, carbohydrate ligands and their complementary lectin-like immune receptors have been difficult to isolate and characterize. However, the development of ultrasensitive mass spectrometric (MS) techniques for sequencing oligosaccharides, when combined with the use of glycan arrays to define carbohydrate binding specificities, have recently changed the research landscape in this area (Blixt et al., 2004; North et al., 2009). The molecular bases underlying the ability of specific carbohydrate sequences to act as functional groups that suppress immune function are now being revealed and previous predictions about these relationships are being validated (Clark et al., 1996, 1997).

Ultrasensitive MS profiling of the N-glycans associated with human sperm and seminal plasma has uncovered the expression of unusual glycans (Pang et al., 2007, 2009). A distinguishing feature of these glycans is the presence of Lewis ${ }^{\mathrm{x}}$ and Lewis ${ }^{\mathrm{y}}$ sequences that are rarely found on the oligosaccharides present on the surface of other normal cell and tissue types outside of the male reproductive system. These sequences are displayed in multivalent presentations on the terminal ends of biantennary, triantennary, and tetraantennary $\mathrm{N}$-glycans (Figure 1). The $\mathrm{N}$-glycans linked to the human ZP are similar, except that they are terminated with multivalent SLEX rather than Lewis ${ }^{\mathrm{x}}$ or Lewis ${ }^{\mathrm{y}}$ sequences (Pang et al., 2011).

The endogenous glycoprotein ligands for immune type lectins have been proposed to be the true mediators of immune homeostasis (Garcia-Vallejo and van Kooyk, 2009). There are four 
Table 2 | Effects of $\mathrm{PGE}_{2}$ on immune function.

\begin{tabular}{|c|c|}
\hline Immunological effects & References \\
\hline $\begin{array}{l}\text { Limits the phagocytic activity of alveolar macrophages and their pathogen killing } \\
\text { function }\end{array}$ & Hubbard et al., 2010 \\
\hline Promotes the tissue influx of neutrophils, macrophages, and mast cells & Yu and Chadee, 1998; Nakayama et al., 2006; Weller et al., 2007 \\
\hline Converts DCs to myeloid derived suppressor cells & Obermajer et al., 2011 \\
\hline Blocks NK cell production of IFN- $\gamma$, inhibiting NK cell helper function & Mailliard et al., 2005 \\
\hline Disrupts early stages of differentiation of dendritic cells (DCs) & Kaliński et al., 1997 \\
\hline Promotes the induction of mast cells and their local attraction and degranulation & Hu et al., 1995; Gomi et al., 2000 \\
\hline Directly inhibits T cell production of IL-2 and IL-2 responsiveness & Walker et al., 1983 \\
\hline Enhances the production of Th2-attracting chemokines & Mcllroy et al., 2006 \\
\hline Inhibits early stages of B cell activation and Ig class switching & Simkin et al., 1987 \\
\hline Limits migration of DCs via induction of tissue inhibitor of proteinase- 1 & Baratelli et al., 2004 \\
\hline Increases the expression of IL-10, thrombospondin and IDO in DCs & Kaliński et al., 1997; Doyen et al., 2003; Braun et al., 2005 \\
\hline $\begin{array}{l}\text { Promotes the maturation of DCs with an impaired ability to induce CTL-, Th1- and } \\
\text { NK cell-mediated type } 1 \text { immunity }\end{array}$ & Kaliński et al., 1998, 1999; Gustafsson et al., 2008 \\
\hline Suppresses the level of bioactive IL-12p70 & Kaliński et al., 1998 \\
\hline Blocks the ability of DCs to attract naïve T cells & Muthuswamy et al., 2010 \\
\hline Suppresses the production of IL-12 in monocytes and DCs & van der Pouw Kraan et al., 1995; Kaliński et al., 1997, 1998 \\
\hline Blocks the expression of the IL-12 receptor in monocytes and DCs & Wu et al., 1998 \\
\hline $\begin{array}{l}\text { Required for the development of tumor associated suppressive macrophages and } \\
\text { myeloid-derived suppressor cells }\end{array}$ & Heusinkveld et al., 2011; Obermajer et al., 2011 \\
\hline Induces the expression of IL-10 in tissue macrophages & Huang et al., 1998; Stolina et al., 2000 \\
\hline Suppress the production of retinoic acid in gut-associated DCs & Stock et al., 2011 \\
\hline
\end{tabular}

major glycoproteins in human seminal plasma that have been identified as endogenous ligands for DC-SIGN, an immune lectin associated with DCs. They include clusterin, galectin-3 binding protein, prostatic acid phosphatase, and protein $\mathrm{C}$ inhibitor (Clark et al., 2012). The exact function of these glycoproteins remains to be determined, but studies with parasites and other persistent pathogens that express Lewis ${ }^{\mathrm{x}}$ and Lewis ${ }^{\mathrm{y}}$ sequences suggest that they are likely involved in the induction of tolerance to the developing human in utero (Garcia-Vallejo and van Kooyk, 2009).

\section{OTHER FACTORS IN SEMINAL PLASMA}

A number of other seminal plasma factors display immunosuppressive effects in vitro. The primary assay that has been employed to assess this effect is the inhibition of phytohemagglutinin (PHA)-induced proliferation of T lymphocytes. Prostasomes are a group of $40-500 \mathrm{~nm}$ membranous vesicles secreted by the prostate into human semen. Prostasomes inhibit PHA-induced proliferation by $69 \%$ in a dose dependent manner (Kelly et al., 1991). However, human prostasomes contain galelectin-3, which could compete with phytohemagglutinin for binding to galactoseterminated glycans on T cell glycoproteins (Jones et al., 2010), so it is possible that this effect could involve a simple lectin blockade rather than a specific immunosuppressive effect. Whether prostasomes mediate a specific immunosuppressive effect remains to be verified.

Still another study indicated that human seminal plasma components with a MW $>3.5 \mathrm{kDa}$ also inhibit PHA-induced 
T lymphocyte proliferation (Ochsenkuhn et al., 2006). While seminal plasma glycoproteins could also inhibit PHA binding to $\mathrm{T}$ lymphocytes via non-specific lectin blockade, an antibody directed against TGF- $\beta$ has been shown to inhibit this immunosuppressive activity by $50 \%$, indicating that this specific cytokine could be partially responsible for this effect (Ochsenkuhn et al., 2006). The immune deviating effects of seminal plasma glycoproteins certainly deserve further attention.

Polyamines in seminal plasma have also been implicated in the suppression of immune responses in the female reproductive tract (Allen and Roberts, 1986). Spermine is present in millimolar concentrations in human seminal plasma (Agostinelli et al., 2007). Supplementation of lymphocyte cultures with spermine leads to a cytotoxic effect that mimics that seen after addition of seminal plasma (Allen and Roberts, 1987). Spermine inhibits LAK cell activity directed against cervical carcinoma cells by up to $60 \%$ at concentrations exceeding $10 \mathrm{nM}$ (Evans et al., 1995). Although the precise mechanisms underlying this finding remain unclear, the deamination of spermine by amine oxidases generates both hydrogen peroxides and aldehydes that promote apoptosis (Agostinelli et al., 2007).

\section{CONCLUSIONS}

Humans have a complex immune system consisting of both innate and adaptive arms and immune cells have developed intricate means of recognizing each other that involve HLA class I and class II molecules. Further complexity is introduced by the diversification of these molecules into many haplotypes to enable exceptionally precise recognition of self in the immunological context. However, this diversity may come at a cost, as it makes the paternal antigen-expressing human fetus the equivalent of a foreign organ transplant within the immunocompetent gravid female (Reisner et al., 2011). The maternal immune system cannot simply be inactivated to allow for reproduction because of the incumbent risk of infection, particularly that arising in the complex microbiologic milieu of the lower genital tract. A compromise state must therefore be established that will allow selective immune privilege for gametes and the developing fetus within the context of an otherwise immunocompetent female reproductive system. A reasonable, though not fully potent, immune response to pathogens must persist to protect the mother from infection.

The pathways that promote immune privilege are best understood in the eye (Streilein, 2003; Niederkorn, 2012). Niederkorn recently proposed an attractive hypothesis that suggests that metastatic uveal melanoma cells found in the liver have "plagiarized" the blueprints employed for ocular immune privilege to create "ad hoc" immune privileged regions in this distant site (Niederkorn, 2012). Obviously, there are enormous advantages for metastatic cells if this hypothesis is correct, as it likely is.

The proposal was made some time ago that a similar type of immune privilege exists for human gametes and the uteroplacental unit (Clark et al., 1996, 1997). Both SLEX and the Lewis $^{y}$ carbohydrate sequences were originally defined as tumorassociated carbohydrate antigens, based on their specific expression on cancer cells but not on their progenitor cells (Abe et al., 1983; Fukushima et al., 1984). A recent study has confirmed the profligate expression of SLEX sequences on the human ZP (Pang et al., 2011). Lewis ${ }^{y}$ sequences are similarly expressed on human sperm and seminal plasma glycoproteins (Pang et al., 2007, 2009). The strong possibility exists that pathogens can also hijack those elements of immune privilege utilized in the reproductive system of humans to evade the immune response. For example, variants of $H$. pylori that express Lewis ${ }^{\mathrm{x}} /$ Lewis $^{\mathrm{y}}$ sequences $^{-}$ on their lipopolysaccharides promote tolerance, whereas nonexpressors evoke the severe inflammatory responses that result in the pathological symptoms associated with this bacterial pathogen (Bergman et al., 2006). HIV infection substantially increases the percentage of $\mathrm{CD}^{+}{ }^{+}$and $\mathrm{CD} 8^{+} \mathrm{T}$ cells that express the Lewis ${ }^{\mathrm{y}}$ sequence (Adachi et al., 1988; Kashiwagi et al., 1994), a characteristic that may allow for relatively unfettered viral proliferation.

It is a substantial challenge to understand how carbohydrate sequences act as functional groups to mediate immunomodulatory effects at the fetomaternal interface. One major obstacle has been the inability to sequence glycans from small amounts of glycoproteins, such as MHC class I molecules. Major advances in mass spectrometry have recently led to the complete structural analysis of native human ZP glycans by Dell and coworkers, a feat performed with only $5 \mu \mathrm{g}$ of purified ZP (Pang et al., 2011). HLA-G expressed on EVTB is differentially glycosylated when compared to classical MHC molecules (McMaster et al., 1998). If HLA-G glycans act as crucial functional groups, then aberrant glycosylation could result in the pathological effects observed during pregnancy. Current molecular and proteomic strategies could never detect these glycobiological changes.

How the information in such carbohydrate signals is transmitted in immune cells must also be defined. Siglecs usually bear specific ITIM that mediate immune modulatory effects via conventional signaling mechanisms (Crocker et al., 2007). The two exceptions (Siglec H and Siglec 14) activate immune cells by interacting with the membrane protein, DAP12 (Angata et al., 2006; Blasius et al., 2006). Other C-type lectin-like receptor complexes are also expressed on NK cells, including the CD94/NKG2 family receptors that employ ITIM/ITAM (immunoreceptor tyrosine-based motif) dependent pathways (Borrego et al., 2006). Carbohydrate ligands for CD94 and NKG2 have not been defined, but neither have the glycans associated with naturally occurring MHC class I molecules that could interact with these lectins. The effects of galectins are more subtle and complex, because they can form lattices of different glycoproteins that promote signaling via both lectin-like and protein-protein interactions (Lau and Dennis, 2008). Since there are many galectins, the potential for establishing functional pathways by organizing such glycoprotein complexes on cell surfaces is substantial (Than et al., 2012).

In summary, these findings suggest that investigation of the pathways that evoke immune privileged states in humans could lead to an understanding of the mechanisms that enable pathogens and tumor cells to evade the immune response. Once such pathways are defined, they can hopefully be readily targeted for therapeutic intervention. The role of carbohydrate recognition in such processes is now beginning to be fully appreciated. 


\section{REFERENCES}

Abe, K., McKibbin, J. M., and Hakomori, S. (1983). The monoclonal antibody directed to difucosylated type 2 chain (Fuc $\alpha 1$ 2GalB1-4[Fuc $\alpha$ 1-3] GlcNAc; Y Determinant). J. Biol. Chem. 258, 11793-11797.

Adachi, M., Hayami, M., Kashiwagi, N., Mizuta, T., Ohta, Y., Gill, M. J., et al. (1988). Expression of Ley antigen in human immunodeficiency virusinfected human $\mathrm{T}$ cell lines and in peripheral lymphocytes of patients with acquired immune deficiency syndrome (AIDS) and AIDS-related complex (ARC). J. Exp. Med. 167, 323-331.

Agostinelli, E., Tempera, G., Molinari, A., Salvi, M., Battaglia, V., Toninello, A., et al. (2007). The physiological role of biogenic amines redox reactions in mitochondria. New perspectives in cancer therapy. Amino Acids 33, 175-187.

Allen, R. D., and Roberts, T. K. (1986). The relationship between the immunosuppressive and cytotoxic effects of human seminal plasma. Am. J. Reprod. Immunol. Microbiol. 11, 59-64.

Allen, R. D., and Roberts, T. K. (1987). Role of spermine in the cytotoxic effects of seminal plasma. Am. J. Reprod. Immunol. Microbiol. 13, 4-8.

Aluvihare, V. R., Kallikourdis, M., and Betz, A. G. (2004). Regulatory $\mathrm{T}$ cells mediate maternal tolerance to the fetus. Nat. Immunol. 5, 266-271.

Angata, T., Hayakawa, T., Yamanaka, M., Varki, A., and Nakamura, M. (2006). Discovery of Siglec-14, a novel sialic acid receptor undergoing concerted evolution with Siglec-5 in primates. FASEB J. 20, 1964-1973.

Angata, T., and Varki, A. (2000). Cloning, characterization, and phylogenetic analysis of siglec-9, a new member of the CD33-related group of siglecs. Evidence for co-evolution with sialic acid synthesis pathways. J. Biol. Chem. 275, 22127-22135.

Apps, R., Gardner, L., and Moffett, A. (2008). A critical look at HLA-G. Trends Immunol. 29, 313-321.

Apps, R., Sharkey, A., Gardner, L., Male, V., Kennedy, P., Masters, L., et al. (2011). Ex vivo functional responses to HLA-G differ between blood and decidual NK cells. Mol. Hum. Reprod. 17, 577-586.

Arruvito, L., Sanz, M., Banham, A. H., and Fainboim, L. (2007). Expansion of CD4+CD25+and FOXP3+ regulatory $\mathrm{T}$ cells during the follicular phase of the menstrual cycle: implications for human reproduction. J. Immunol. 178, 2572-2578.

Avril, T., Floyd, H., Lopez, F., Vivier, E., and Crocker, P. R. (2004). The membrane-proximal immunoreceptor tyrosine-based inhibitory motif is critical for the inhibitory signaling mediated by Siglecs- 7 and -9 , CD33-related Siglecs expressed on human monocytes and NK cells. J. Immunol. 173, 6841-6849.

Baban, B., Chandler, P., McCool, D. Marshall, B., Munn, D. H., and Mellor, A. L. (2004). Indoleamine 2, 3-dioxygenase expression is restricted to fetal trophoblast giant cells during murine gestation and is maternal genome specific. J. Reprod. Immunol. 61, 67-77.

Bankhurst, A. D. (1982). The modulation of human natural killer cell activity by prostaglandins. J. Clin. Lab. Immunol. 7, 85-91.

Baratelli, F., Lin, Y., Zhu, L., Yang, S. C., Heuze-Vourc'h, N., Zeng, G., et al. (2005). Prostaglandin E2 induces FOXP3 gene expression and $\mathrm{T}$ regulatory cell function in human CD4+ T cells. J. Immunol. 175, 1483-1490.

Baratelli, F. E., Heuze-Vourc'h, N., Krysan, K., Dohadwala, M., Riedl, K., Sharma, S., et al. (2004) Prostaglandin E2-dependent enhancement of tissue inhibitors of metalloproteinases- 1 production limits dendritic cell migration through extracellular matrix. J. Immunol. 173, 5458-5466.

Barondes, S. H., Castronovo, V., Cooper, D. N., Cummings, R. D., Drickamer, K., Feizi, T., et al. (1994). Galectins: a family of animal beta-galactoside-binding lectins. Cell 76, 597-598.

Basso, O., Christensen, K., and Olsen, J. (2001). Higher risk of pre-eclampsia after change of partner. An effect of longer interpregnancy intervals? Epidemiology 12, 624-629.

Bast, R. C. Jr., Feeney, M., Lazarus, H., Nadler, L. M., Colvin, R. B., and Knapp, R. C. (1981). Reactivity of a monoclonal antibody with human ovarian carcinoma. J. Clin. Invest. 68, 1331-1337.

Bast, R. C. Jr., Klug, T. L., St. John, E. Jenison, E., Niloff, J. M., Lazarus, H., et al. (1983). A radioimmunoassay using a monoclonal antibody to monitor the course of epithelial ovarian cancer. N. Engl. J. Med. 309, 883-887.

Beer, A. E., and Billingham, R. E. (1971). Immunobiology of mammalian reproduction. $A d v$. Immunol. 14, 1-84.

Benirschke, K. (1994). Anatomical relationship between fetus and mother. Ann. N.Y. Acad. Sci. 731, 9-20.
Bergman, M., Del Prete, G., van Kooyk, Y., and Appelmelk, B. (2006). Helicobacter pylori phase variation, immune modulation and gastric autoimmunity. Nat. Rev. Microbiol. 4, 151-159.

Bergmann, C., Strauss, L., Zeidler, R., Lang, S., and Whiteside, T. L. (2007). Expansion of human $\mathrm{T}$ regulatory type 1 cells in the microenvironment of cyclooxygenase 2 overexpressing head and neck squamous cell carcinoma. Cancer Res. 67, 8865-8873.

Bian, C. F., Zhang, Y., Sun, H., Li, D. F., and Wang, D. C. (2011) Structural basis for distinct binding properties of the human galectins to Thomsen-Friedenreich antigen. PLoS ONE 6:e25007. doi: 10.1371/journal.pone.0025007

Blaschitz, A., Juch, H., Volz, A., Hutter, H., Daxboeck, C., Desoye, G. et al. (2005). The soluble pool of HLA-G produced by human trophoblasts does not include detectable levels of the intron 4-containing HLA-G5 and HLA-G6 isoforms. Mol. Hum. Reprod. 11, 699-710.

Blasius, A. L., Cella, M., Maldonado, J., Takai, T., and Colonna, M. (2006). Siglec-H is an IPC-specific receptor that modulates type I IFN secretion through DAP12. Blood 107, 2474-2476.

Blixt, O., Head, S., Mondala, T. Scanlan, C., Huflejt, M. E., Alvarez, R., et al. (2004). Printed covalent glycan array for ligand profiling of diverse glycan binding proteins. Proc. Natl. Acad. Sci. U.S.A. 101, 17033-17038

Blois, S. M., Ilarregui, J. M., Tometten, M., Garcia, M., Orsal, A. S., CordoRusso, R., et al. (2007). A pivotal role for galectin-1 in fetomaternal tolerance. Nat. Med. 13, 1450-1457.

Bluestone, J. A., and Tang, Q. (2005) How do CD4+CD25+ regulatory T cells control autoimmunity? Curr. Opin. Immunol. 17, 638-642.

Bohn, H., Kraus, W., and Winckler, W. (1983). Purification and characterization of two new soluble placental tissue proteins (PP13 and PP17). Oncodev. Biol. Med. 4, 343-350.

Boniface, K., Bak-Jensen, K. S., Li, Y., Blumenschein, W. M., McGeachy, M. J., McClanahan, T. K., et al. (2009). Prostaglandin E2 regulates Th17 cell differentiation and function through cyclic AMP and EP2/EP4 receptor signaling. J. Exp. Med. 206, 535-548.

Borrego, F., Masilamani, M., Marusina, A. I., Tang, X., and Coligan, J. E. (2006). The CD94/NKG2 family of receptors: from molecules and cells to clinical relevance. Immunol. Res. 35, 263-278.

Braun, D., Longman, R. S., and Albert, M. L. (2005). A two-step induction of indoleamine 2, 3 dioxygenase (IDO) activity during dendriticcell maturation. Blood 106, 2375-2381.

Burton, G. J., and Jauniaux, E. (2004) Placental oxidative stress: from miscarriage to preeclampsia. J. Soc. Gynecol. Investig. 11, 342-352.

Carini, C., Hudspith, B. N., and Brostoff, J. (1981). Effect of prostaglandins and cyclic nucleotides on growth and immunoglobulin secretion of two IgE myeloma cell lines. $\mathrm{Br}$. J. Cancer 43, 257-260.

Chazara, O., Xiong, S., and Moffett, A. (2011). Maternal KIR and fetal HLA-C: a fine balance. J. Leukoc. Biol. 90, 703-716.

Chiu, P. C., Chung, M. K., Tsang, H. Y., Koistinen, R., Koistinen, H., Seppala, M., et al. (2005). Glycodelin-S in human seminal plasma reduces cholesterol efflux and inhibits capacitation of spermatozoa. J. Biol. Chem. 280 25580-25589.

Clark, G. F. (2010). The mammalian zona pellucida: a matrix that mediates both gamete binding and immune recognition? Syst. Biol. Reprod. Med. 56, 349-364.

Clark, G. F., Dell, A., Morris, H. R., Patankar, M., Oehninger, S., and Seppala, M. (1997). Viewing AIDS from a glycobiological perspective: potential linkages to the human fetoembryonic defence system hypothesis. Mol. Hum. Reprod. $3,5-13$.

Clark, G. F., Grassi, P., Pang, P. C., Panico, M., Lafrenz, D., Drobnis, E. Z., et al. (2012). Tumor biomarker glycoproteins in the seminal plasma of healthy human males are endogenous ligands for DC-SIGN. Mol Cell. Proteomics 11:M111.008730. doi: 10.1074/mcp.M111.008730

Clark, G. F., Oehninger, S., Patankar, M. S., Koistinen, R., Dell, A., Morris, H R., et al. (1996). A role for glycoconjugates in human development: the human feto- embryonic defence system hypothesis. Hum. Reprod. 11, 467-473.

Crocker, P. R., Paulson, J. C., and Varki, A. (2007). Siglecs and their roles in the immune system. Nat. Rev. Immunol. 7, 255-266.

Dalton, C. F., Laird, S. M., Serle, E., Saravelos, H., Warren, M A., Li, T. C., et al. (1995). The measurement of CA 125 and placental protein 14 in uterine flushings in women with recurrent 
miscarriage; relation to endometrial morphology. Hum. Reprod. 10, 2680-2684.

Dell, A., Morris, H. R., Easton, R. L., Panico, M., Patankar, M., Oehniger, S., et al. (1995). Structural analysis of the oligosaccharides derived from glycodelin, a human glycoprotein with potent immunosuppressive and contraceptive activities. J. Biol. Chem. 270, 24116-24126.

Doyen, V., Rubio, M., Braun, D., Nakajima, T., Abe, J., Saito, H., et al. (2003). Thrombospondin 1 is an autocrine negative regulator of human dendritic cell activation. J. Exp. Med. 198, 1277-1283.

Drake, P. M., Gunn, M. D., Charo, I. F., Tsou, C. L., Zhou, Y., Huang, L., et al. (2001). Human placental cytotrophoblasts attract monocytes and CD56(bright) natural killer cells via the actions of monocyte inflammatory protein 1alpha. J. Exp. Med. 193, 1199-1212.

Drobnis, E. Z., and Overstreet, J. W. (1992). Natural history of mammalian spermatozoa in the female reproductive tract. Oxf. Rev. Reprod. Biol. 14, 1-45.

Dym, M. (1973). The fine structure of the monkey (Macaca) Sertoli cell and its role in maintaining the blood-testis barrier. Anat. Rec. 175, 639-656.

Earle, K. E., Tang, Q., Zhou, X., Liu, W., Zhu, S., Bonyhadi, M. L., et al. (2005). In vitro expanded human CD4+CD25+ regulatory T cells suppress effector $\mathrm{T}$ cell proliferation. Clin. Immunol. 115, 3-9.

Easton, R. L., Patankar, M. S., Clark, G. F., Morris, H. R., and Dell, A. (2000). Pregnancy-associated changes in the glycosylation of Tamm-Horsfall glycoprotein. Expression of sialyl Lewisx sequence on core 2 type $\mathrm{O}$-glycans derived from uromodulin. J. Biol. Chem. 275, 21928-21938.

Esaki, Y., Li, Y., Sakata, D., Yao, C., Segi-Nishida, E., Matsuoka, T., et al. (2010). Dual roles of PGE2EP4 signaling in mouse experimental autoimmune encephalomyelitis. Proc. Natl. Acad. Sci. U.S.A. 107, 12233-12238.

Evans, C. H., Lee, T. S., and Flugelman, A. A. (1995). Spermine-directed immunosuppression of cervical carcinoma cell sensitivity to a majority of lymphokine-activated killer lymphocyte cytotoxicity. Nat. Immun. 14, 157-163.

Ewoldsen, M. A., Ostlie, N. S., and Warner, C. M. (1987). Killing of mouse blastocyst stage embryos by cytotoxic $\mathrm{T}$ lymphocytes directed to major histocompatibility complex antigens. J. Immunol. 138, 2764-2770.

Favier, B., Lemaoult, J., and Carosella, E. D. (2007a). Functions of HLA$\mathrm{G}$ in the immune system. Tissue Antigens 69(Suppl. 1), 150-152.

Favier, B., Lemaoult, J., Rouas-Freiss, N., Moreau, P., Menier, C., and Carosella, E. D. (2007b). Research on HLA-G: an update. Tissue Antigens 69, 207-211.

Fedder, J. (1996). Nonsperm cells in human semen: with special reference to seminal leukocytes and their possible influence on fertility. Arch. Androl. 36, 41-65.

Fijak, M., and Meinhardt, A. (2006). The testis in immune privilege. Immunol. Rev. 213, 66-81.

Fox, C. A., Meldrum, S. J., and Watson, B. W. (1973). Continuous measurement by radio-telemetry of vaginal $\mathrm{pH}$ during human coitus. J. Reprod. Fertil. 33, 69-75.

Foxall, C., Watson, S. R., Dowbenko, D., Fennie, C., Lasky, L. A., Kiso, M., et al. (1992). The three members of the selectin receptor family recognize a common carbohydrate epitope, the sialyl Lewis ${ }^{\mathrm{x}}$ oligosaccharide. J. Cell Biol. 117, 895-902.

Fukuda, M., Hiraoka, N., and Yeh, J. C. (1999). C-type lectins and sialyl Lewis X oligosaccharides. Versatile roles in cell-cell interaction. J. Cell Biol. 147, 467-470.

Fukushima, K., Hirota, M., Terasaki, P. I., Wakisaka, A., Togashi, H., Chia, D., et al. (1984). Characterization of sialosylated Lewis ${ }^{\mathrm{x}}$ as a new tumorassociated antigen. Cancer Res. 44, 5279-5285.

Garcia-Vallejo, J. J., and van Kooyk, Y. (2009). Endogenous ligands for C-type lectin receptors: the true regulators of immune homeostasis. Immunol. Rev. 230, 22-37.

Georgiades, P., Ferguson-Smith, A C., and Burton, G. J. (2002). Comparative developmental anatomy of the murine and human definitive placentae. Placenta 23, 3-19.

Ghiringhelli, F., Menard, C., Martin, F. and Zitvogel, L. (2006). The role of regulatory $\mathrm{T}$ cells in the control of natural killer cells: relevance during tumor progression. Immunol. Rev. 214, 229-238.

Goldblatt, M. W. (1935). Properties of human seminal plasma. J. Physiol. 84, 208-218.

Gomi, K., Zhu, F. G., and Marshall, J. S. (2000). Prostaglandin E2 selectively enhances the IgE-mediated productin of IL-6 and granulocytemacrophase colony-stimulating factor by mast cells through an
EP1/EP3-dependent mechanism. J. Immunol. 165, 6545-6552.

Goto, T., Herberman, R. B., Maluish, A., and Strong, D. M. (1983). Cyclic AMP as a mediator of prostaglandin E-induced suppression of human natural killer cell activity. J. Immunol. 130, 1350-1355.

Grinnell, B. W., Hermann, R. B., and Yan, S. B. (1994). Human protein C inhibits selectin-mediated cell adhesion: role of unique fucosylated oligosaccharide. Glycobiology 4, 221-225.

Gubbels, J. A., Felder, M., Horibata, S., Belisle, J. A., Kapur, A., Holden, H., et al. (2010). MUC16 provides immune protection by inhibiting synapse formation between NK and ovarian tumor cells. Mol. Cancer 9:11. doi: 10.1186/1476-4598-9-11

Gupta, S. K., Mountain, L., and Alexander, N. J. (1988). Seminal plasma antigens detected by immunoblotting with human sera from vasectomized males. J. Reprod. Immunol. 12, 263-276.

Gustafsson, K., Ingelsten, M., Bergqvist, L., Nystrom, J., Andersson, B. and Karlsson-Parra, A. (2008). Recruitment and activation of natural killer cells in vitro by a human dendritic cell vaccine. Cancer Res. $68,5965-5971$

He, J., and Baum, L. G. (2006) Endothelial cell expression of galectin-1 induced by prostate cancer cells inhibits T-cell transendothelial migration. Lab. Invest. 86, 578-590.

Head, J. R., and Billingham, R. E. (1985). Immunologically privileged sites in transplantation immunology and oncology. Perspect. Biol. Med. 29, 115-131.

Hession, C., Decker, J. M., Sherblom, A. P., Kumar, S., Yue, C. C., Mattaliano, R. J., et al. (1987). Uromodulin (Tamm-Horsfall glycoprotein): a renal ligand for lymphokines. Science 237, 1479-1484.

Heusinkveld, M., de Vos van Steenwijk, P. J., Goedemans, R. Ramwadhdoebe, T. H., Gorter, A., Welters, M. J., et al. (2011). M2 macrophages induced by prostaglandin E2 and IL-6 from cervical carcinoma are switched to activated M1 macrophages by CD4+ Th1 cells. J. Immunol. 187 1157-1165.

Hu, Z. Q., Asano, K., Seki, H., and Shimanura, T. (1995). An essential role of prostaglandin $\mathrm{E}$ on mouse mast cell induction. J. Immunol. $155,2134-2142$

Huang, M., Stolina, M., Sharma, S., Mao, J. T., Zhu, L., Miller, P. W. et al. (1998). Non-small cell lung cancer cyclooxygenase-2-dependent regulation of cytokine balance in lymphocytes and macrophages: up-regulation of interleukin 10 and down-regulation of interleukin 12 production. Cancer Res. 58, 1208-1216.

Hubbard, L. L., Ballinger, M. N., Thomas, P. E., Wilke, C. A., Standiford, T. J., Kobayashi, K. S., et al. (2010). A role for IL1 receptor-associated kinase-M in prostaglandin E2-induced immunosuppression postbone marrow transplantation. J. Immunol. 184, 6299-6308.

Hunt, J. S. (2006). Stranger in a strange land. Immunol. Rev. 213, 36-47.

Hutter, H., and Dohr, G. (1998). HLA expression on immature and mature human germ cells. J. Reprod. Immunol. 38, 101-122.

Hutter, H., Hammer, A., Blaschitz, A., Hartmann, M., Ebbesen, P., Dohr, G., et al. (1996). Expression of HLA class I molecules in human first trimester and term placenta trophoblast. Cell Tissue Res. 286, 439-447.

Ilarregui, J. M., Croci, D. O., Bianco, G. A., Toscano, M. A., Salatino, M., Vermeulen, M. E., et al. (2009). Tolerogenic signals delivered by dendritic cells to $\mathrm{T}$ cells through a galectin-1-driven immunoregulatory circuit involving interleukin 27 and interleukin 10. Nat. Immunol. 10, 981-991.

Ish-Shalom, E., Gargir, A., Andre, S., Borovsky, Z., Ochanuna, Z., Gabius, H. J., et al. (2006). alpha2, 6-Sialylation promotes binding of placental protein 14 via its $\mathrm{Ca} 2+$-dependent lectin activity: insights into differential effects on CD45RO and CD45RA T cells. Glycobiology 16, 173-183.

Jeschke, U., Wang, X., Briese, V., Friese, K., and Stahn, R. (2003). Glycodelin and amniotic fluid transferrin as inhibitors of E-selectin-mediated cell adhesion. Histochem. Cell Biol. 119, 345-354.

Jones, J. L., Saraswati, S., Block, A. S., Lichti, C. F., Mahadevan, M., and Diekman, A. B. (2010). Galectin3 is associated with prostasomes in human semen. Glycoconj. J. 27, 227-236.

Jonuleit, H., Kuhn, U., Muller, G., Steinbrink, K., Paragnik, L. Schmitt, E., et al. (1997). Proinflammatory cytokines and prostaglandins induce maturation of potent immunostimulatory dendritic cells under fetal calf 
serum-free conditions. Eur. Kelly, R. W., Taylor, P. L., Hearn, J. Immunol. 27, 3135-3142.

Joshi, P. C., Zhou, X., Cuchens, M., and Jones, Q. (2001). Prostaglandin E2 suppressed IL-15-mediated human NK cell function through downregulation of common gammachain. J. Immunol. 166, 885-891.

Juch, H., Blaschitz, A., Dohr, G., and Hutter, H. (2012). HLA class I expression in the human placenta. Wien. Med. Wochenschr. 162, 196-200.

Julkunen, M., Rutanen, E. M., Koskimies, A., Ranta, T., Bohn, H., and Seppala, M. (1985). Distribution of placental protein 14 in tissues and body fluids during pregnancy. Br. J. Obstet. Gynaecol. 92, 1145-1151.

Kaliński, P., Hilkens, C. M., Snijders, A., Snijdewint, F. G., and Kapsenberg, M. L. (1997). IL-12-deficient dendritic cells, generated in the presence of prostaglandin E2, promote type 2 cytokine production in maturing human naive $\mathrm{T}$ helper cells. J. Immunol. 159, 28-35.

Kaliński, P., Hilkens, C. M., Wierenga, E. A., and Kapsenberg, M. L. (1999). T-cell priming by type-1 and type-2 polarized dendritic cells: the concept of a third signal. Immunol. Today 20, 561-567.

Kaliński, P., Schuitemaker, J. H., Hilkens, C. M., and Kapsenberg, M. L. (1998). Prostaglandin E2 induces the final maturation of IL-12-deficient CDla+CD83+ dendritic cells: the levels of IL-12 are determined during the final dendritic cell maturation and are resistant to further modulation. J. Immunol. 161, 2804-2809.

Kamimura, S., Eguchi, K., Yonezawa, M., and Sekiba, K. (1991). Localization and developmental change of indoleamine 2, 3dioxygenase activity in the human placenta. Acta Med. Okayama 45, 135-139.

Karre, K. (1991). MHC gene control of the natural killer system at the level of the target and the host. Semin. Cancer Biol. 2, 295-309.

Kashiwagi, N., Gill, M. J., Adachi, M., Church, D., Wong, S. J., Poon, M. C., et al. (1994). Lymphocyte membrane modifications induced by HIV infection. Tohoku J. Exp. Med. 173, 115-131.

Kelly, R. W., Holland, P., Skibinski, G., Harrison, C., McMillan, L., Hargreave, T., et al. (1991). Extracellular organelles (prostasomes) are immunosuppressive components of human semen. Clin. Exp. Immunol. 86, 550-556.
J. P., Short, R. V., Martin, D. E., and Marston, J. H. (1976). 19-Hydroxyprostaglandin E1 as a major component of the semen of primates. Nature 260, 544-545.

Kho, E. M., McCowan, L. M., North, R. A., Roberts, C. T., Chan, E., Black, M. A., et al. (2009). Duration of sexual relationship and its effect on preeclampsia and small for gestational age perinatal outcome. J. Reprod. Immunol. 82, 66-73.

King, A., Allan, D. S., Bowen, M., Powis, S. J., Joseph, S., Verma, S. et al. (2000). HLA-E is expressed on trophoblast and interacts with CD94/NKG2 receptors on decidual NK cells. Eur. J. Immunol. 30, 1623-1631.

King, A., Birkby, C., and Loke, Y. W. (1989). Early human decidual cells exhibit NK activity against the K562 cell line but not against first trimester trophoblast. Cell. Immunol. 118, 337-344.

King, A., Burrows, T., and Loke, Y. W. (1996). Human uterine natural killer cells. Nat. Immun. 15, 41-52.

King, A., Burrows, T., Verma, S., Hiby, S., and Loke, Y. W. (1998). Human uterine lymphocytes. Hum. Reprod. Update 4, 480-485.

King, A., and Loke, Y. W. (1990). Human trophoblast and JEG choriocarcinoma cells are sensitive to lysis by IL-2-stimulated decidual NK cells. Cell. Immunol. 129, 435-448.

Krensky, A. M., Weiss, A., Crabtree, G., Davis, M. M., and Parham, P. (1990). T-lymphocyte-antigen interactions in transplant rejection. N. Engl. J. Med. 322, 510-517.

Kui Wong, N., Easton, R. L., Panico, M., Sutton-Smith, M., Morrison, J. C., Lattanzio, F. A., et al. (2003). Characterization of the oligosaccharides associated with the human ovarian tumor marker CA125. J. Biol. Chem. 278, 28619-28634.

Kuo, P. L., Hung, J. Y., Huang, S. K., Chou, S. H., Cheng, D. E., Jong, Y. J., et al. (2011). Lung cancer-derived galectin-1 mediates dendritic cell anergy through inhibitor of DNA binding 3/IL-10 signaling pathway. J. Immunol. 186, 1521-1530.

Lala, P. K., Kennedy, T. G., and Parhar, R. S. (1988). Suppression of lymphocyte alloreactivity by early gestational human decidua. II. Characterization of the suppressor mechanisms. Cell. Immunol. 116, 411-422.

Lau, K. S., and Dennis, J. W. (2008). $\mathrm{N}$-Glycans in cancer progression. Glycobiology 18, 750-760.
Lee, C. L., Lam, E. Y., Lam, K. K., Koistinen, H., Seppala, M., Ng, E. H., et al. (2012). Glycodelin-A stimulates interleukin-6 secretion by human monocytes and macrophages through L-selectin and the extracellular signalregulated kinase pathway. J. Biol. Chem. 287, 36999-37009.

Lee, C. L., Pang, P. C., Yeung, W. S., Tissot, B., Panico, M., Lao, T. T., et al. (2009). Effects of differential glycosylation of glycodelins on lymphocyte survival. J. Biol. Chem. 284 , 15084-15096.

Leibovitz, A., Baumoehl, Y., and Segal, R. (2004). Increased incidence of pathological and clinical prostate cancer with age: age related alterations of local immune surveillance. J. Urol. 172, 435-437.

Li, N., Wang, T., and Han, D. (2012). Structural, cellular and molecular aspects of immune privilege in the testis. Front. Immun. 3:152. doi: 10.3389/fimmu.2012.00152

Lombardo, F., Gandini, L., Dondero, F., and Lenzi, A. (2001). Antisperm immunity in natural and assisted reproduction. Hum. Reprod. Update 7, 450-456.

Luft, T., Jefford, M., Luetjens, P. Toy, T., Hochrein, H., Masterman, K. A., et al. (2002). Functionally distinct dendritic cell (DC) populations induced by physiologic stimuli: prostaglandin $\mathrm{E}(2)$ regulates the migratory capacity of specific DC subsets. Blood 100, 1362-1372.

Maegawa, M., Kamada, M., Irahara, M., Yamamoto, S., Yoshikawa, S., Kasai, Y., et al. (2002). A repertoire of cytokines in human seminal plasma. J. Reprod. Immunol. 54, 33-42.

Mailliard, R. B., Alber, S. M., Shen, H., Watkins, S. C., Kirkwood, J. M., Herberman, R. B., et al. (2005). IL-18-induced CD83+CCR7+ NK helper cells. J. Exp. Med. 202, 941-953.

McIlroy, A., Caron, G., Blanchard, S., Fremaux, I., Duluc, D., Delneste, Y., et al. (2006). Histamine and prostaglandin E up-regulate the production of Th2-attracting chemokines (CCL17 and CCL22) and down-regulate IFN-gammainduced CXCL10 production by immature human dendritic cells. Immunology 117, 507-516.

McMaster, M., Zhou, Y., Shorter, S., Kapasi, K., Geraghty, D., Lim, K. H., et al. (1998). HLA-G isoforms produced by placental cytotrophoblasts and found in amniotic fluid are due to unusual glycosylation. J. Immunol. 160, 5922-5928.

Medawar, P. (1953). Some immunological and endocrinological problems raised by the evolution of viviparity in vertebrates. Symp. Soc. Exp. Biol. 7, 320-338.

Meekins, J. W., Luckas, M. J., Pijnenborg, R., and McFadyen, I. R. (1997). Histological study of decidual spiral arteries and the presence of maternal erythrocytes in the intervillous space during the first trimester of normal human pregnancy. Placenta 18, 459-464.

Morris, H. R., Dell, A., Easton, R. L., Panico, M., Koistinen, H. Koistinen, R., et al. (1996). Genderspecific glycosylation of human glycodelin affects its contraceptive activity. J. Biol. Chem. 271, 32159-32167.

Motran, C. C., Molinder, K. M., Liu, S. D., Poirier, F., and Miceli, M. C. (2008). Galectin-1 functions as a Th2 cytokine that selectively induces Th1 apoptosis and promotes Th2 function. Eur. J. Immunol. 38, 3015-3027.

Mukhopadhyay, D., Sundereshan, S., Rao, C., and Karande, A. A. (2001). Placental protein 14 induces apoptosis in T cells but not in monocytes. J. Biol. Chem. 276, 28268-28273.

Muldoon, L. L., Alvarez, J. I., Begley, D. J., Boado, R. J., Del Zoppo, G. J., Doolittle, N. D., et al. (2013). Immunologic privilege in the central nervous system and the bloodbrain barrier. J. Cereb. Blood Flow Metab. 33, 13-21.

Munn, D. H., and Armstrong, E. (1993). Cytokine regulation of human monocyte differentiation in vitro: the tumor-cytotoxic phenotype induced by macrophage colony-stimulating factor is developmentally regulated by gamma-interferon. Cancer Res. 53, 2603-2613.

Munn, D. H., Zhou, M., Attwood, J. T., Bondarev, I., Conway, S. J., Marshall, B., et al. (1998). Prevention of allogeneic fetal rejection by tryptophan catabolism Science 281, 1191-1193.

Muthuswamy, R., Mueller-Berghaus, J., Haberkorn, U., Reinhart, T. A., Schadendorf, D., and Kalinski, P. (2010). PGE2 transiently enhances DC expression of CCR7 but inhibits the ability of DCs to produce CCL19 and attract naive T cells. Blood 116, 1454-1459.

Muthuswamy, R., Urban, J., Lee, J. J., Reinhart, T. A., Bartlett, D., and Kalinski, P. (2008). Ability of mature dendritic cells to interact with regulatory $\mathrm{T}$ cells is imprinted during maturation. Cancer Res. 68, 5972-5978.

Nakayama, T., Mutsuga, N., Yao, L., and Tosato, G. (2006). Prostaglandin 
E2 promotes degranulationindependent release of MCP-1 from mast cells. J. Leukoc. Biol. 79, 95-104.

Neaves, W. B., and Billingham, R. E. (1979). The lymphatic drainage of the rat prostate and its status as an immunologically privileged site. Transplantation 27, 127-132.

Niederkorn, J. Y. (2012). Ocular immune privilege and ocular melanoma: parallel universes or immunological plagiarism? Front. Immun. 3:148. doi: 10.3389/fimmu.2012.00148

Nocera, M., and Chu, T. M. (1993). Transforming growth factor beta as an immunosuppressive protein in human seminal plasma. Am. J. Reprod. Immunol. 30, 1-8.

Nocera, M., and Chu, T. M. (1995). Characterization of latent transforming growth factor-beta from human seminal plasma. Am. J. Reprod. Immunol. 33, 282-291.

Norling, L. V., Sampaio, A. L., Cooper, D., and Perretti, M. (2008). Inhibitory control of endothelial galectin-1 on in vitro and in vivo lymphocyte trafficking. FASEB $J$. $22,682-690$.

North, S. J., Hitchen, P. G., Haslam, S. M., and Dell, A. (2009). Mass spectrometry in the analysis of $\mathrm{N}$-linked and O-linked glycans. Curr. Opin. Struct. Biol. 19, 498-506.

Obermajer, N., Muthuswamy, R., Lesnock, J., Edwards, R. P., and Kalinski, P. (2011). Positive feedback between PGE2 and COX2 redirects the differentiation of human dendritic cells toward stable myeloid-derived suppressor cells. Blood 118, 5498-5505.

Ochsenkuhn, R., O'Connor, A. E., Hirst, J. J., Gordon Baker, H. W., De Kretser, D. M., and Hedger, M. P. (2006). The relationship between immunosuppressive activity and immunoregulatory cytokines in seminal plasma: influence of sperm autoimmunity and seminal leukocytes. J. Reprod. Immunol. 71, 57-74.

Okamoto, N., Uchida, A., Takakura, K., Kariya, Y., Kanzaki, H., Riittinen, L., et al. (1991). Suppression by human placental protein 14 of natural killer cell activity. Am. J. Reprod. Immunol. 26, 137-142.

Pandya, I. J., and Cohen, J. (1985). The leukocytic reaction of the human uterine cervix to spermatozoa. Fertil. Steril. 43, 417-421.

Pang, P. C., Chiu, P. C., Lee, C. L., Chang, L. Y., Panico, M., Morris, H. R., et al. (2011). Human sperm binding is mediated by the sialyl-Lewis ${ }^{\mathrm{x}}$ oligosaccharide on the zona pellucida. Science 333, 1761-1764.

Pang, P. C., Tissot, B., Drobnis, E. Z., Morris, H. R., Dell, A., and Clark, G. F. (2009). Analysis of the human seminal plasma glycome reveals the presence of immunomodulatory carbohydrate functional groups. J. Proteome Res. 8, 4906-4915.

Pang, P. C., Tissot, B., Drobnis, E. Z., Sutovsky, P., Morris, H. R., Clark, G. F., et al. (2007). Expression of bisecting type and Lewisx/Lewisy terminated N-glycans on human sperm. J. Biol. Chem. 282, 36593-36602.

Parhar, R. S., and Lala, P. K. (1988). Prostaglandin E2-mediated inactivation of various killer lineage cells by tumor-bearing host macrophages. J. Leukoc. Biol. 44, 474-484.

Patankar, M. S., Yu, J., Morrison, J. C., Belisle, J. A., Lattanzio, F. A., Deng, Y., et al. (2005). Potent suppression of natural killer cell response mediated by the ovarian tumor marker CA125. Gynecol. Oncol. 99, 704-713.

Pennington, K. A., Schlitt, J. M., Jackson, D. L., Schulz, L. C., and Schust, D. J. (2012). Preeclampsia: multiple approaches for a multifactorial disease. Dis. Model. Mech. 5 9-18.

Perillo, N. L., Pace, K. E., Seilhamer, J. J., and Baum, L. G. (1995). Apoptosis of $\mathrm{T}$ cells mediated by galectin- 1 . Nature 378, 736-739.

Pockley, A. G., and Bolton, A. E. (1989). Placental protein 14 (PP14) inhibits the synthesis of interleukin-2 and the release of soluble interleukin-2 receptors from phytohaemagglutinin-stimulated lymphocytes. Clin. Exp. Immunol. 77, 252-256.

Pockley, A. G., Mowles, E. A., Stoker, R. J., Westwood, O. M., Chapman, M. G., and Bolton, A. E. (1988). Suppression of in vitro lymphocyte reactivity to phytohemagglutinin by placental protein 14. J. Reprod. Immunol. 13, 31-39.

Rajagopalan, S., and Long, E. O. (1999). A human histocompatibility leukocyte antigen (HLA)-G-specific receptor expressed on all natural killer cells. J. Exp. Med. 189, 1093-1100.

Reisner, Y., Hagin, D., and Martelli, M. F. (2011). Haploidentical hematopoietic transplantation: current status and future perspectives. Blood 118, 6006-6017.

Rieser, C., Bock, G., Klocker, H. Bartsch, G., and Thurnher, M. (1997). Prostaglandin E2 and tumor necrosis factor alpha cooperate to activate human dendritic cells: synergistic activation of interleukin 12 production. J. Exp. Med. 186 1603-1608.

Rumke, P., and Hellinga, G. (1959) Autoantibodies against spermatozoa in sterile men. Am. J. Clin. Pathol. 32, 357-363.

Saari, T., Jahnukainen, K., and Pollanen, P. (1996). Autoantigenicity of the basal compartment of seminiferous tubules in the rat. J. Reprod. Immunol. 31, 65-79.

Samuelsson, B. (1963). Isolation and identification of prostaglandins from human seminal plasma. 18 prostaglandins and related factors. J. Biol. Chem. 238, 3229-3234.

Sargent, I. L. (2005). Does 'soluble' HLA-G really exist? Another twist to the tale. Mol. Hum. Reprod. 11, 695-698.

Sasaki, Y., Sakai, M., Miyazaki, S. Higuma, S., Shiozaki, A., and Saito, S. (2004). Decidual and peripheral blood CD4+CD25+ regulatory $\mathrm{T}$ cells in early pregnancy subjects and spontaneous abortion cases. Mol. Hum. Reprod. 10 347-353.

Scandella, E., Men, Y., Gillessen, S. Forster, R., and Groettrup, M. (2002). Prostaglandin E2 is a key factor for CCR7 surface expression and migration of monocytederived dendritic cells. Blood 100 1354-1361.

Setchell, B. P. (1967). The bloodtesticular fluid barrier in sheep. J. Physiol. 189, 63P-65P

Sharkey, D. J., Macpherson, A. M. Tremellen, K. P., Mottershead, D. G. Gilchrist, R. B., and Robertson, S. A (2012a). TGF-beta mediates proinflammatory seminal fluid signaling in human cervical epithelial cells. J. Immunol. 189, 1024-1035.

Sharkey, D. J., Tremellen, K. P., Jasper, M. J., Gemzell-Danielsson, K., and Robertson, S. A. (2012b). Seminal fluid induces leukocyte recruitment and cytokine and chemokine mRNA expression in the human cervix after coitus. J. Immunol. 188 , 2445-2454.

Sheibanie, A. F., Yen, J. H., Khayrullina, T., Emig, F., Zhang, M., Tuma, R. et al. (2007). The proinflammatory effect of prostaglandin E2 in experimental inflammatory bowel disease is mediated through the IL-23 $\rightarrow$ IL17 axis. J. Immunol. 178, 8138-8147.

Shima, T., Sasaki, Y., Itoh, M. Nakashima, A., Ishii, N., Sugamura, K., et al. (2010). Regulatory T cells are necessary for implantation and maintenance of early pregnancy but not late pregnancy in allogeneic mice. J. Reprod. Immunol. 85, 121-129.

Simkin, N. J., Jelinek, D. F., and Lipsky, P. E. (1987). Inhibition of human B cell responsiveness by prostaglandin E2. J. Immunol. 138, 1074-1081.

Smith, R. J. (1977). Modulation of phagocytosis by and lysosomal enzyme secretion from guinea-pig neutrophils: effect of nonsteroid anti-inflammatory agents and prostaglindins. J. Pharmacol. Exp. Ther. 200, 647-657.

Specht, C., Bexten, S., Kolsch, E., and Pauels, H. G. (2001). Prostaglandins, but not tumorderived IL-10, shut down concomitant tumor-specific CTL responses during murine plasmacytoma progression. Int. J. Cancer 91, 705-712.

Stock, A., Booth, S., and Cerundolo, V. (2011). Prostaglandin E2 suppresses the differentiation of retinoic acidproducing dendritic cells in mice and humans. J. Exp. Med. 208, 761-773.

Stolina, M., Sharma, S., Lin, Y., Dohadwala, M., Gardner, B., Luo, J., et al. (2000). Specific inhibition of cyclooxygenase 2 restores antitumor reactivity by altering the balance of IL-10 and IL-12 synthesis. J. Immunol. 164, 361-370.

Stowell, S. R., Karmakar, S., Stowell, C. J., Dias-Baruffi, M., McEver, R. P., and Cummings, R. D. (2007). Human galectin-1, -2 , and -4 induce surface exposure of phosphatidylserine in activated human neutrophils but not in activated T cells. Blood 109, 219-227.

Streilein, J. W. (1995). Unraveling immune privilege. Science 270, 1158-1159.

Streilein, J. W. (2003). Ocular immune privilege: therapeutic opportunities from an experiment of nature. Nat. Rev. Immunol. 3, 879-889.

Sublett, J. W., and Bernstein, J. A. (2011). Seminal plasma hypersensitivity reactions: an updated review. Mt. Sinai J. Med. 78, 803-809.

Tamm, I., and Horsfall, F. L. (1950). Characterization and separation of an inhibitor of viral hemagglutination present in urine. Proc. Soc. Exp. Biol. Med. 74, 108-114.

Taylor, P. L., and Kelly, R. W. (1974). 19-Hydroxylated E prostaglandins as the major prostaglandins of human semen. Nature 250, 665-667.

Templeton, A. A., Cooper, I., and Kelly, R. W. (1978). Prostaglandin concentrations in the semen of fertile men. J. Reprod. Fertil. 52, 147-150.

Than, N. G., Romero, R., Kim, C. J., McGowen, M. R., Papp, Z., and 
Wildman, D. E. (2012). Galectins: guardians of eutherian pregnancy at the maternal-fetal interface. Trends Endocrinol. Metab. 23, 23-31.

Thompson, L. A., Barratt, C. L., Bolton, A. E., and Cooke, I. D. (1992). The leukocytic reaction of the human uterine cervix. Am. J. Reprod. Immunol. 28, 85-89.

Tirado-Gonzalez, I., Freitag, N., Barrientos, G., Shaikly, V., Nagaeva, O., Strand, M., et al. (2013). Galectin-1 influences trophoblast immune evasion and emerges as a predictive factor for the outcome of pregnancy. Mol. Hum. Reprod. 19, 43-53.

Tirado-Gonzalez, I., MunozFernandez, R., Prados, A., Leno-Duran, E., Martin, F., Abadia-Molina, A. C., et al. (2012). Apoptotic DC-SIGN+ cells in normal human decidua. Placenta 33, 257-263.

Toscano, M. A., Bianco, G. A., Ilarregui, J. M., Croci, D. O., Correale, J., Hernandez, J. D., et al. (2007). Differential glycosylation of $\mathrm{TH} 1$, TH2 and TH-17 effector cells selectively regulates susceptibility to cell death. Nat. Immunol. 8, 825-834.

Tung, K. S., Teuscher, C., and Meng, A. L. (1981). Autoimmunity to spermatozoa and the testis. Immunol. Rev. 55, 217-255.

van der Pouw Kraan, T. C., Boeije, L. C., Smeenk, R. J., Wijdenes, J., and Aarden, L. A. (1995). ProstaglandinE2 is a potent inhibitor of human interleukin 12 production. J. Exp. Med. 181, 775-779.

van Dooremaal, J. C. (1873). Die Entwicklung der in fremden Grund versetzten lebenden
Geweba. Albrecht von Graefes Arch. Ophthalmol. 19, 358-373.

van Liempt, E., Bank, C. M., Mehta, P., Garcia-Vallejo, J. J., Kawar, Z. S., Geyer, R., et al. (2006). Specificity of DC-SIGN for mannose- and fucosecontaining glycans. FEBS Lett. 580, 6123-6131.

von Euler, U. (1935). Über die Spezifische Blutdrucksenkende Substanz des Menschlichen Prostata- und Samenblasensekretes. Wien Klin Wochenschr 14 1182-1183.

von Euler, U. S. (1936). On the specific vasodilating and plain muscle stimulating substances from the accessory genital glands in man and certain animals (prostaglandins and vesiglandin). J. Physiol. (Lond.) 88, 213-234.

Wakefield, L. M., Smith, D. M., Masui, T., Harris, C. C., and Sporn, M. B. (1987). Distribution and modulation of the cellular receptor for transforming growth factor-beta. J. Cell Biol. 105, 965-975.

Walker, C., Kristense, F., Bettens, F., and Deweck, A. L. (1983). Lymphokine regulation of activated (G1) lymphocytes, I: prostaglandin E2-induced inhibition of interleukin 2 production. J. Immunol. 130, 1770-1773.

Walker, W., and Rotondo, D. (2004). Prostaglandin E2 is a potent regulator of interleukin-12- and interleukin-18-induced natural killer cell interferon-gamma synthesis. Immunology 111, 298-305.

Watchmaker, P. B., Berk, E., Muthuswamy, R., Mailliard, R.
B., Urban, J. A., Kirkwood, J. M., et al. (2010). Independent regulation of chemokine responsiveness and cytolytic function versus CD8+ $\mathrm{T}$ cell expansion by dendritic cells. J. Immunol. 184, 591-597.

Weller, C. L., Collington, S. J., Hartnell, A., Conroy, D. M., Kaise, T., Barker, J. E., et al. (2007). Chemotactic action of prostaglandin E2 on mouse mast cells acting via the PGE2 receptor 3. Proc. Natl. Acad. Sci. U.S.A. 104, 11712-11717.

Woolard, M. D., Hensley, L. L. Kawula, T. H., and Frelinger, J. A. (2008). Respiratory Francisella tularensis live vaccine strain infection induces Th17 cells and prostaglandin E2, which inhibits generation of gamma interferonpositive T cells. Infect. Immun. 76, 2651-2659.

Wu, C. Y., Wang, K., McDyer, J. F., and Seder, R. A. (1998). Prostaglandin E2 and dexamethasone inhibit IL12 receptor expression and IL-12 responsiveness. J. Immunol. 161, 2723-2730.

Yaniv, E., Borovsky, Z., MishanEisenberg, G., and Rachmilewitz, J. (2003). Placental protein 14 regulates selective B cell responses. Cell. Immunol. 222, 156-163.

Yin, B. W., Dnistrian, A., and Lloyd, K. O. (2002). Ovarian cancer antigen CA125 is encoded by the MUC16 mucin gene. Int. J. Cancer 98, 737-740.

Yu, Y., and Chadee, K. (1998) Prostaglandin E2 stimulates IL8 gene expression in human colonic epithelial cells by a posttranscriptional mechanism. J. Immunol. 161, 3746-3752.
Yule, T. D., Montoya, G. D., Russell, L. D., Williams, T. M., and Tung, K. S. (1988). Autoantigenic germ cells exist outside the blood testis barrier. J. Immunol. 141, 1161-1167.

Zinkernagel, R. M., and Doherty, P. C. (1974). Restriction of in vitro $\mathrm{T}$ cell-mediated cytotoxicity in lymphocytic choriomeningitis within a syngeneic or semiallogeneic system. Nature 248, 701-702.

Conflict of Interest Statement: The authors declare that the research was conducted in the absence of any commercial or financial relationships that could be construed as a potential conflict of interest.

Received: 07 December 2012; paper pending published: 21 December 2012; accepted: 22 January 2013; published online: 13 February 2013.

Citation: Clark GF and Schust DJ (2013) Manifestations of immune tolerance in the human female reproductive tract. Front. Immun. 4:26. doi: 10.3389/ fimmu.2013.00026

This article was submitted to Frontiers in Immunological Tolerance, a specialty of Frontiers in Immunology.

Copyright (C) 2013 Clark and Schust. This is an open-access article distributed under the terms of the Creative Commons Attribution License, which permits use, distribution and reproduction in other forums, provided the original authors and source are credited and subject to any copyright notices concerning any third-party graphics etc. 